\title{
Ima li smisla vjerovati u smisao?*
}

Ivan Kordić**

ivan.kordic1@zg.htnet.hr
UDK: 234.2

233.5

Izlaganje sa znanstvenog skupa / Conference paper

Primljeno: 25. lipnja 2016.

Prihvaćeno: 15. srpnja 2016.

Vjera u Boga usko je povezana s pitanjem o smislu ljudskoga života. Ova teza ovdje se razvija prije svega na temelju mišljenja njemačkog filozofa Volkera Gerhardta. Pritom se posebno ističe da je dimenzija bezuvjetnosti smisla stvaran životni element religije i da se racionalnost vjere i pitanja smisla može prikazati na prikladan način, za što veliko značenje može imati i promišljanje tradicije racionalne teologije. Ovdje se vjera razumijeva kao egzistencijalan čin koji obuhvaća čovjeka kao cjelinu, a ta se cjelina odnosi na život kao cjelinu i na svijet kao takav. Ovaj se čin može odnositi i na Boga kao osobu, čija spoznaja nadilazi čovjeka i njegove sposobnosti, bilo da on pokušava dokazati njegovu egzistenciju, bilo da je niječe. Stoga se ovdje pokušava pokazati da Boga nije moguće u potpunosti razumjeti, da je on u biti više stvar vjere nego znanja, a da vjera $i$ znanje jedno drugome ipak ne protuslove, da nisu neki antipodi, nego tvore jedinstvo koje je potpora samosvjesnom čovjekovu djelovanju. Time se sugerira da put prema onom božanskom, odnosno prema Bogu, ima i teorijsku i praktičnu razinu, no da i jedna i druga dotiču tajnu koja doduše nadilazi čovjekovu spoznajnu moć, ali je ne ostavlja u nekakvoj potpunoj nemoći. Stoga se vjera promatra kao pozitivna stvarnost, a kritika religija je, koliko god ona u mnogočemu bila opravdana, temeljito stavljena u pitanje.

Ključne riječi: smisao, vjera, racionalnost, znanje, Bog, božansko, teorija, praksa, kritika religije.

\footnotetext{
* Izlaganje na znanstvenom simpoziju Godišnje konferencije Udruge za promicanje filozofije, pod naslovom: »Božje postojanje i Božji atributi«, održane 23.-24. lipnja 2016. u Zagrebu, uz suorganizaciju Hrvatskih studija Sveučilišta u Zagrebu, a cjelovit će tekst biti objavljen u zborniku simpozija.

${ }^{* *}$ Dr. sc. Ivan Kordić je redoviti profesor u trajnom izboru, znanstveni savjetnik na Institutu za filozofiju, Ulica grada Vukovara 54, HR-10000 Zagreb.
} 
Suvremeni njemački filozof Volker Gerhardt pokušava pokazati da je vjera u Boga usko povezana s pitanjem o smislu ljudskoga života i s odgovorom na to pitanje. Pritom polazi od toga da svako iščekivanje nekog smisla ima povjerenje u smisao onoga što jest, a taj smisao svoj temelj nalazi u cjelini stvarnosti kao takve. Pod utjecajem ovoga smisla čovjek pak stječe sigurnost da je on onaj koji doista jest, da bi onda, kad mu se učini važnim, nadišao samoga sebe. ${ }^{1}$ No, za karakteriziranje ovoga općeg smisla, koji utemeljuje čovjekov životni tijek u cjelini, za njega ne postoji bolji pojam od pojma onoga božanskoga. A gdje čovjeku uspije prema ovom božanskom uspostaviti vjernički odnos, koji ga se osobno tiče, on ovo božansko može nazvati i Bogom, protiv čega istinska filozofija ne može imati nikakav prigovor koji bi pojedincu njegovo vjerovanje učinio besmislenim. ${ }^{2}$

U pozadini ovih razmišljanja očito stoji uvjerenje da čovjek vrlo slabo razumije sebe i svijet, ako se odrekne pitanja o smislu svoga življenja, mišljenja i djelovanja. Naime, ozbiljno shvaćeno pitanje o smislu vodi prema nosivom temelju svih čovjeku bitnih perspektiva koje se tiču smisla njegova postojanja. ${ }^{3}$ Pa kad Ludwig Wittgenstein zastupa mišljenje da je pitanje o smislu života odgovoreno čim bude zaboravljeno, da se rješenje problema u biti primijeti "pri nestanku nekog problema ${ }^{4},{ }^{4}$ onda prema Gerhardtu pojam smisla gubi svaku filozofsku relevantnost. Stoga sebi u ovom kontekstu dopušta pomalo provokativnu ironiju, koja, čini se, ipak pogađa bit problema:

»Da je Wittgenstein ostao inženjer, onda bi se njegova tvrdnja mogla pripisati profesionalnoj deformaciji; no, budući da ju je izrekao kao filozof i da ju je često ponavljao, onda je potrebno zapitati se zašto i druga filozofska pitanja nije rješavao njihovim zaboravom. ${ }^{5}$

Čovjek je, prema Gerhardtu, jedino biće koje može žuditi za onim božanskim ili Bogom i koje je čak u stanju osjećati se tim bliže svome cilju što se osjeća gore. Jer, ovo božansko mu omogućuje da zanemari sve nedostatke svoga postojanja. A kao čovjek on Boga može spoznavati samo ljudskim sredstvima. Pritom može misliti i djelovati i približiti se onom božanskom, a da ga nikada ne shvati u potpunosti. ${ }^{6}$ On samo može reći kako Boga razumije, a da ne zna je li tu riječ o istinskoj spoznaji, on se može složiti s drugim ljudima da ono božansko promatra kao izvorište, bit, temelj ili cilj koji nadilazi svijet, a da ne zna može li biti siguran u svoje shvaćanje. Sigurno znanje postoji naime samo u obliku iskaza o predmetima kojima Bog po svom pojmu ne pripada. Stoga ljudsko

\footnotetext{
${ }^{1}$ Usp. Volker GERHARDT, Der Sinn des Sinns. Versuch über das Göttliche, München, Verlag C. H. Beck, 2014, 23.

${ }^{2}$ Usp. isto, 24.

${ }^{3}$ Usp. isto, 25.

${ }^{4}$ Ludwig WITTGENSTEIN, Tractatus logico-philosophicus, Frankfurt a. M., Suhrkamp, 1979, 114-115.

${ }^{5}$ Gerhardt, Der Sinn des Sinns..., 135.

${ }^{6}$ Usp. isto, 209.
} 
znanje u njegovim sintetičkim i analitičkim ostvarenjima, u kojima se, kao u logici i matematici, događa organiziranje njegovih funkcija, nije dostatno da bi moglo postići čvrstu sigurnost o onom božanskom. No, to ne znači da čovjek sebi treba zabraniti svako razmišljanje o njemu ${ }^{7}$ i da se na ovom području mora odreći težnje za spoznajom, koliko god se ona pokazivala nesigurnom.

Ova nesigurnost spoznaje onoga božanskoga, čovjeka dovodi i do uvjerenja da se Bog kao izvor, bit, temelj i cilj svijeta mora nalaziti izvan njega, da je on transcendentno biće koje je nastanjeno s onu stranu svijeta, pa upravo zbog toga i ne može biti predmet sigurnoga znanja. Nasuprot tome, vjera ustrajava na mogućnosti pristupa onom božanskom, i to između ostaloga i tako da se pouzdanim sredstvima može stvarati zaključke o Bogu i njegovoj transcendenciji. Ipak valja priznati da sve ovo ne može voditi ni do teorijski ni do praktično pouzdanih iskaza o onom božanskom. Jer, ako se želi vjerovati da je Bog temelj ljudskoga postojanja i izvorište ljudskoga života, onda ga se ne može razumjeti kao transcendentnu veličinu s onu stranu svijeta. A prema Gerhardtu valja biti svjestan nemogućnosti i nekog zasebnog Božjeg postojanja unutar svijeta, kao i nesuvislosti njegove izvansvjetske pozicije, da bi se postiglo neko primjereno razumijevanje Boga, pri kojem čovjek ne bi bio u protuslovlju sa samim sobom i sa svojim spoznajnim moćima. ${ }^{8}$ Bog ili ono božansko mora se naime prema njemu prikazati kao nešto što je djelotvorno unutar svijeta. Inače Bog za čovjeka, koji bez odnosa prema svijetu i bez povjerenja u njega ne može djelovati, ne bi imao nikakvo značenje. ${ }^{9}$

Gerhardt je dakle mišljenja da Boga ne treba razumjeti ni kao nešto u svijetu ni kao nešto izvan svijeta. Njega se, prema njemu, može razumjeti samo kao organ svijeta u cjelini, onako kako svijet mora razumjeti čovjek ukoliko sebe želi shvatiti kao razumijevajući i spoznavajući dio toga svijeta. Tako shvaćeni Bog je naime tu za svijet, u kojem čovjek pod uvjetima osobno usmjerene vjere želi sebe poznavati i u njemu se dobro osjećati. ${ }^{10}$ Jer, koliko god se moderan čovjek nalazio na vrhuncu svoga znanja, on ipak mora priznati da ono nikad neće biti dostatno da bi on svoj odnos prema svijetu mogao regulirati samo na osnovi toga znanja. On se naime nalazi pred ponorom znanja. Ovaj ponor on prema Gerhardtu može preskočiti samo vjerom, samo vjerom može istupiti iz nepreglednog mnoštva odnosa koji ga okružuju, da bi se cjelini svijeta mogao obratiti s povjerenjem kao samome sebi. ${ }^{11}$

Prema Gerhardtu, vjeruje se u ono što nije moguće u potpunosti misliti i znati. Pritom čovjek s povjerenjem prihvaća neki stečeni uvid i dopušta da ga vodi ono što stoji na granicama znanja, a što označava kao cjelinu, jedno,

\footnotetext{
7 Usp. isto, 210.

8 Usp. isto, 211-212.

${ }^{9}$ Usp. isto, 228.

${ }^{10}$ Usp. isto, 230.

${ }^{11}$ Usp. isto, 246.
} 
sve, totalitet, bitak, prirodu ili stvarnost, ${ }^{12}$ ali i kao Boga ili ono božansko, iako bi možda $\mathrm{s}$ Heideggerom ponekad s pravom o Bogu najradije šutio. ${ }^{13}$ Vjera dakle može stupiti na mjesto znanja, na mjesto na kojem znanje udara o svoje granice. ${ }^{14}$ Čovjek može doduše mnogo znati i smije očekivati da će se obzori njegova znanja proširivati. Tim bolnije je za njega iskustvo da ne može znati sve i da će to uvijek tako ostati. Što god naime više zna, to mu je jasnije da gotovo ništa ne zna. Stoga se vjera kao odnos prema znanju ne može razumijevati kao privremeni nadomjestak, koji će postati suvišan kad znanje pokrije sva područja koja čovjeka zanimaju. Ona se mora shvatiti i kao dopuna onim što znanje uskraćuje upravo onome tko zna. ${ }^{15}$

Uostalom, za Heideggera je mišljenje prije svega mišljenje bitka, odnosno smisla bitka, a ne bića, koje može biti predmet znanstvenog istraživanja. A ovaj uvid ga je doveo do njegove poznate i snažno osporavane tvrdnje da znanost ne misli, a koja je i za njega bila upitna i stvar stalnog propitivanja. ${ }^{16}$ Stoga ju je uvijek nanovo pokušavao dopuniti i razjasniti. Pritom ističe da pojedini znanstveni istraživači doduše mogu misliti, ali ne metodom svojega istraživanja kao znanstvenici, kao poznavatelji bića, nego kao mislioci bitka. Stoga ni njegova tvrdnja nije nikakav prijezir znanosti, budući da ona nije nikakvo utvrđivanje činjenica, nego svojevrsno istraživanje biti, prema kojem znanost, način bivstvovanja svoga područja kao takvoga, ne može imati za temu istraživanja. ${ }^{17}$ Znanosti naime unutar svojih granica ne mogu određivati bit svoga područja istraživanja, budući da im je ono u njima nezaobilazno, npr. priroda, čovjek, povijest, jezik, u svojoj biti jednostavno nedostupno. ${ }^{18} \mathrm{Tu}$ je naime riječ o bitku, koji očito nadilazi i čovjeka, kao i predmet njegova znanja i mišljenja, ali smisao svega što jest ipak daje naslutiti i misliti. A ovaj smisao može se nazvati i Bogom ili onim božanskim u što se može vjerovati.

Unatoč svemu tome, ili upravo zbog svega toga, znanje i vjerovanje nisu nikakvi antipodi, koliko god se međusobno razlikovali. Oni za Gerhardta tvore jedinstvo koje povezuje čovjekovo samosvjesno djelovanje i koje je djelotvorno u svemu onome što on sa sigurnošću i s uvjerenjem čini, ${ }^{19}$ budući da je i on sam jedinstvo koje zna, vjeruje, misli, sluti, siguran je i nesiguran. Toga bi čovjek trebao biti svjestan, posebno u vremenu u kojem opseg znanja postaje sve veći, ali se sve jasnije pokazuju i njegove praznine. Stoga onaj tko nešto zna mora

\footnotetext{
${ }^{12}$ Usp. isto, 44.

${ }^{13}$ Usp. Martin HEIDEGGER, Identität und Differenz, GA 11, Frankfurt a. M., Vittorio Klostermann, 2006, 63.

${ }^{14}$ Usp. Gerhardt, Der Sinn des Sinns..., 166.

${ }^{15}$ Usp. isto, 193.

${ }^{16}$ Usp. Martin HEIDEGGER, Was heißt Denken?, GA 8, Frankfurt a. M., Vittorio Klostermann, 2002, 9.

${ }^{17}$ Usp. isto, 9a.

${ }^{18}$ Usp. Martin HEIDEGGER, Vorträge und Aufsätze, GA 7, Frankfurt a. M., Vittorio Klostermann, 2000, 60 .

${ }^{19}$ Usp. Gerhardt, Der Sinn des Sinns..., 57.
} 
moći svjesno živjeti s činjenicom svoga neznanja, koja tek znanjem postaje očitom..$^{20}$ Inače može početi vjerovati da će jednoga dana svojim znanjem moći nadići i vjeru. A za Gerhardta nema ništa gluplje od upravo ove vjere. ${ }^{21}$ Jer, i vjera posjeduje svoju obuhvatnu racionalnu strukturu koju prema Jürgenu Habermasu može i treba respektirati i profani um. ${ }^{22}$

Stoga Gerhardt vjeru želi na različite načine i u različitom smislu pokazati u njezinoj racionalnosti i predstaviti je kao smislenu. No, pritom on ima veliko razumijevanje i za kritiku religije, koja nerijetko može biti od pomoći protiv zloporabe i krivog razumijevanja smisla vjere. Stoga podsjeća da je Nietzscheov Antikrist obračun koji potječe iz duboke povrijeđenosti i to s onima koji, pozivajući se na Boga, žele rasteretiti sebe i pritom iznalaze opterećenja za druge da bi istovremeno za sebe priskrbili nekakve koristi. I upravo zbog toga za Gerhardta je razumljivo što Nietzsche »Sina Božjega«, »Hebreja Isusa«, kako ga on naziva, koji živi ljubav, izuzima iz ovoga svoga ubitačnoga suda. ${ }^{23}$

Pa iako dakle Gerhardt kritiku religije u mnogočemu smatra opravdanom, on je nerijetko podvrgava oštroj protukritici, pogotovo ako ona operira sa slabim argumentima i pristaje uza stare ili nove ideologije. Tako on u ovom kontekstu, referirajući se na jednu antiklerikalnu reklamu zaklade »Giordano Bruno«, jasno izražava svoju poziciju:

»Tko s pitanjem: 'Još uvijek vjeruješ ili si već počeo misliti?' od vjere i mišljenja pravi alternativu, on samo pokazuje teškoće koje ima ne samo s vjerom, nego očito i s mišljenjem. « ${ }^{24}$

Za njega se naime vjera i mišljenje, vjera i znanje, nalaze u takvom simbiotičkom odnosu da se pri raspadu toga odnosa gube i vjera i znanje. ${ }^{25}$ A kritičari religije nerijetko misle da ovaj odnos mogu raskinuti tako što častohleplje i taštine religioznih institucija izjednačavaju s religijom kao takvom. No, ako se ne podlegne ovoj predrasudi, onda se brzo može uvidjeti da je suprotstavljanje vjere i uma nerijetko utemeljeno na površnim promatranjima, nedostatnom znanju i velikom nepoznavanju vjere. ${ }^{26} \mathrm{~A}$ to je posebno vidljivo onda kad netko misli da znanje i znanost može mobilizirati protiv vjere. Nije naime, prema Gerhardtu, znanost diskreditirala vjeru, nego je to učinila crkvena skepsa prema znanju. ${ }^{27}$ Nasuprot tome, bez vjere nije moguće ozbiljno shvatiti nikakve ideje uma. Ovdje se doduše radi o vjeri koju prema njezinu sadržaju treba razlikovati od vjere u Boga, ali koja u svom temeljnom sadržaju

\footnotetext{
${ }^{20}$ Usp. isto, 59.

${ }^{21}$ Usp. isto, 60.

${ }^{22}$ Usp. Jürgen HABERMAS, Glauben und Wissen, Frankfurt a.M., Suhrkamp, 2001, 28.

${ }^{23}$ Usp. Gerhardt, Der Sinn des Sinns..., 16.

${ }^{24}$ Isto, 41.

${ }^{25}$ Usp. isto, 113.

${ }^{26}$ Usp. isto, 42.

${ }^{27}$ Usp. isto, 96.
} 
nije različita od religiozne vjere. ${ }^{28}$ Uostalom, Kant je na vrhuncu osiguravanja znanstvenog znanja, vjeri nov temelj postavio u umu. ${ }^{29}$

Prema Gerhardtu je teško razumjeti kako je moguće nijekati cjelinu stvarnosti, što se u povijesti filozofije nerijetko događa, budući da se pri ovom nijekanju pokazuje cjelina neke osobe u razgraničenju od cjeline stvarnosti, pri čemu je i osoba ipak cjelina. Unatoč tome, za njega je poučno kad se netko okrene protiv onoga što je očigledno. A isto tako je poučno kad se netko okrene onom očiglednom i tvrdi da ne može postojati Bog, budući da on ne pripada predmetima osjetnog iskustva svijeta. U oba slučaja može se naime naučiti da stvarnost ne postoji samo kao površina, nego da je ona i konstelacija uzroka i posljedica u koje je čovjek kao fizičko biće, kao senzibilni individuuma i kao inteligibilna osoba uvezan i integriran u cjelinu. ${ }^{30} \mathrm{~Pa}$ ako postanemo svjesni ove činjenice, onda je možda moguće razumjeti i Heisenbergovo uvjerenje, ali ga i prihvatiti, da naime prvi gutljaj iz čaše prirodne znanosti čovjeka doduše može učiniti ateistom, jer se pritom usredotočuje prije svega na ono osjetno i na njegovu strukturu, no da na dnu čaše čeka $\operatorname{Bog}^{31}$ koji može biti jedan od odgovora na pitanja koja nameće tajna stvarnosti kao takve.

Jer, i vjera počiva na znanju koje je potrebno ako se želi istinski misliti i djelovati. No, znanje nije dostatno da bi bilo moguće samosvjesno i budućnosti okrenuto djelovanje. Stoga je jasno da za povjerenje u sebe i u primjeren svršetak svoga dobronamjernog i dobrog rada čovjek treba i svojevrsnu vjeru. ${ }^{32}$ Ovo Gerhardta navodi na uvjerenje da je ideološko-kritička podvala religiji da je ona daleko od stvarnosti, da je otuđena od nje, jer zanemaruje racionalni karakter vjere. Prema njemu, jedva da postoji nešto drugo što je više od religije proširilo čovjekov prostor spoznaje o početku i kraju bitka; čovjekova sumnja nikada se nije tako snažno javila kao pri pitanju o temelju i cilju cjeline; nigdje se nije pokazala tako velika preuzetnost kao kod čovjekova htijenja da povjerljivo razgovara sa Stvoriteljem i da ga razumije. A ovo je pitanje i znanja i vjere. Tako i racionalna teologija svoje razumijevanje osobnoga Boga u kojega vjeruje pokušava voditi preko granica ljudske spoznaje, proširiti ga. A ovi pokušaji intenzivirani su i aporijama u koje upada svaki nauk o vjeri koji sebe želi i intelektualno propitivati. ${ }^{33}$

A što se tiče činjenice da tjeskoba i strah imaju veliku ulogu u povijesti religije, što je bilo i ostalo važno područje napada mnogih kritičara kršćanstva, Gerhardt podsjeća na to da tjeskoba i strah u biti pripadaju prirodnom i egzistencijalnom ustroju čovjeka. No, ne može se osporiti ni to da se vjera njima zapravo suprotstavlja, da se njih u vjeri dobrim razlozima može

\footnotetext{
${ }^{28}$ Usp. isto, 134.

${ }^{29}$ Usp. isto, 173.

${ }^{30}$ Usp. isto, 313-314.

${ }^{31}$ Usp. isto, 319.

${ }^{32}$ Usp. isto, 330.

${ }^{33}$ Usp. isto, 332.
} 
prevladati. I budući da vjera, kao odnos prema znanju, strukturalno obvezuje na racionalnost, onda se čovjek upravo zbog sve većih granica znanja i njegove upitnosti iz razumskih razloga mora trsiti oko toga da ne izgubi vjeru. ${ }^{34}$

Vjeri, posebno institucionaliziranoj, često se prigovara da čovjeka vodi u prisilu, da mu oduzima slobodu. Nasuprot tome, Gerhardt je mišljenja da svaka autentična i istinska institucija, ona naime koja podjeljuje nadležnosti i ne temelji se na pukoj prisili, ima rasterećujuću ulogu. Ona čovjeka oslobađa potrebe i nužnosti da sva iskustva sam stječe, da sve iritacije sam doživljava, da sve odluke sam donosi. U tome su religije usporedive s moralnim normama, s državom i sa školama. ${ }^{35}$ Težnja dakle za cjelinom u koju se može imati povjerenje i koja rasterećuje, što je glavna uloga institucija, ne može dakle biti ništa sumnjivo.

No, u ovom kontekstu Gerhardt ne zanemaruje ni drugu stranu ove medalje. On doduše ističe da čovjek samo pozivanjem na cjelinu može biti čovjek koji on jest, da samo ovim pozivanjem može misliti i osjećati, da on bez svijesti o cjelini ne može ni vjerovati. No, ako se vjernik identificira s cjelinom, onda postoji opasnost da postane protivnikom svih drugih i da ih distinkcijama nekog nauka ili kroz opsjednutost vlašću isključuje iz ove cjeline. Tako vjera može postati oružje moćnika. ${ }^{36}$ Pritom može nestati sav humor, koji je potreban, unatoč svoj ozbiljnosti svega. No, ako humor znači i sposobnost da pojedinac i sam sebe može staviti u pitanje, onda je to dobra stvar za sve. Inače su, npr. liječnici koji svoju dijagnozu smatraju nepogrešivom, velika opasnost za pacijente, a teolozi koji glume tajne Božje savjetnike, mogu samo osnivati sekte i nikome ne mogu pomoći. $^{37}$

Vjeri je prema Gerhardtu stalo prije svega do samospoznaje. A tko osjeća obvezu prema ovom sokratovskom zahtjevu, on se ne može zadovoljiti time da se priključi samo Rousseauu, Kantu i Nietzscheu, nego se mora baviti i Augustinom i Meisterom Eckhartom, Montaigneom i Pascalom, ne smije zaboraviti ni Pavla ni autora Ivanova evanđelja. Osim toga, on se pita što bi moglo značiti filozofsko isticanje individualnosti i slobode, transparentnosti i tolerancije, ako bi se iz povijesti vokabulara, koji je nositelj modernoga doba, brisao doprinos kršćanskih mislilaca. ${ }^{38}$ Jer, nijedna druga religija nije tako snažno promicala spoznaju, znanje, djelovanje i individualnu samostalnost kao kršćanstvo. Uza sav respekt prema kritici Voltairea, Humea i Feuerbacha, on želi ostati kod ovog uvjerenja. Osim toga, on je mišljenja da nijedna druga religija deficite racionalne kulture nije posvijestila s toliko snažnom uvjerljivošću kao kršćanstvo. Jer, u njemu sve je ništa bez ljubavi koja ljudskom životu daje

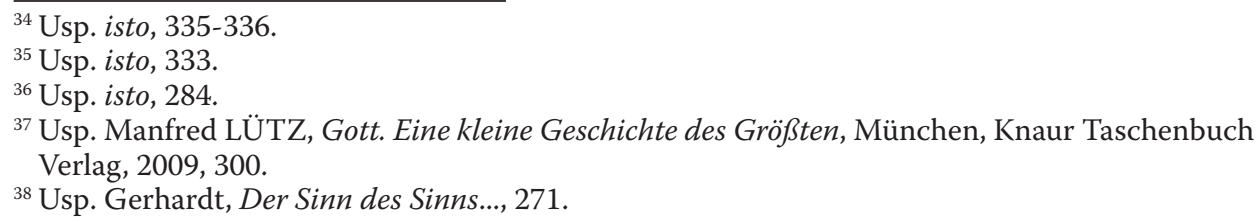


dominantan smisao, koji tijelo i duh ispunja trenutačno i vodi ih i preko granica vremena. ${ }^{39}$

Religiji se često predbacuje da je utočište neuspješnih, neobrazovanih i slabih. Gerhardt priznaje da je Crkva prema Matejevu evanđelju (Mt 11, 28) doduše organizacija za umorne i opterećene, no da to nisu samo gladni, siromašni, protjerani, nego da su to svi ljudi, budući da svi stoje pod znakom smrti, zablude i bolesti. Svi su upućeni na utjehu vjere koja može ohrabrivati i davati snagu za život. ${ }^{40}$ Ona se nudi svima onima koji u svakodnevnim stvarima nemaju povjerenja u sebe i u svijet, ili ga nemaju dovoljno. A za slučajeve $u$ kojima bolest, nevolja, razočaranje, gubitak bližnjega ili blizina smrti mogu sve staviti u pitanje, ona obećava poruku koja, unatoč svemu, jamči smisao. Istina, povjerenje u svijet i u sebe čovjek u pravilu ima od početka svoga postojanja. No, ako ono nestane, on se nema više ni na što osloniti. Stoga bi elementarni cilj svakog odgoja trebao biti: kod mladih jačati povjerenje. A tome može poslužiti i odgoj za vjeru u Boga. ${ }^{41}$

\footnotetext{
${ }^{39}$ Usp. isto, 304.

${ }^{40}$ Usp. isto, 310.

${ }^{41}$ Usp. isto, 273.
} 


\section{Ivan Kordić* \\ Ist es sinnvoll, an den Sinn zu glauben?*** \\ Zusammenfassung}

Der Glaube an Gott ist mit der Frage nach dem Sinn menschlichen Lebens eng verbunden. Diese These wird hier vor allem aufgrund des Denkens des deutschen Philosophen Volker Gerhardt entwickelt. Dabei wird besonders hervorgehoben, dass die Unbedingtheitsdimension von Sinn das eigentliche Lebenselement der Religion ist und dass man die Rationalität des Glaubens und der Sinnfrage ausweisen kann, wozu auch der Bezug auf die Tradition der rationalen Theologie seine Bedeutung hat. Hier wird der Glaube als existenzieller Akt verstanden, der das Ganze des Menschen umfasst und es auf das Ganze seines Lebens und der Welt als solcher bezieht. Dieser Akt kann auch Gott als Person gelten, dessen Erkenntnis den Menschen und sein Vermögen übersteigt, sei es, dass er versucht, Existenz Gottes zu beweisen, sei es, sie zu leugnen. So wird hier versucht zu zeigen, dass man Gott nie völlig verstehen kann, dass er im Grunde mehr die Sache des Glaubens als des Wissens ist und dass sich Glaube und Wissen nicht widersprechen, sie sind keine Antipoden, sondern sie bilden eine Einheit, die das selbstbewusste Handeln des Menschen trägt. Damit wird angedeutet, dass der Weg zum Göttlichen und zu Gott sowohl theoretische als auch praktische Dimension hat, beide aber reichen an das Geheimnis, das menschliches Erkenntnisvermögen zwar übersteigt, es aber nicht in totaler Ohnmacht liegen lässt. So wird der Glaube als eine positive Angelegenheit betrachtet, Religionskritik aber, mag sie in vieler Hinsicht auch berechtigt sein, gründlich in Frage gestellt.

Schlüsselworte: Sinn, Glaube, Rationalität, Wissen, Gott, Göttliches, Theorie, Praxis, Religionskritik.

(na njem. prev. Ivan Kordić)

\footnotetext{
* Prof. Dr. Ivan Kordić ist ordentlicher Professor, Wissenschaftsrat am Institut für Philosophie; Anschrift: Institut za filozofiju, Ulica grada Vukovara 54, HR-10000 Zagreb; E-Mail: ivan.kordic1@zg.htnet.hr.

* Dieser Vortrag wurde auf dem Symposium der Jahreskonferenz von der Vereinigung für Förderung der Philosophie mit dem Thema »Gottesexistenz und Gottesattribute «, in Zagreb, 23.-24. Juni 2016, stattgefunden hat. Der ganze Text wird im Sammelband des Symposiums veröffentlicht werden.
} 